IZA DP No. 6665

Migration, Redistribution and the Universal Welfare Model

Torben M. Andersen

June 2012 


\title{
Migration, Redistribution and the Universal Welfare Model
}

\author{
Torben M. Andersen \\ Aarhus University, \\ CEPR, CESIfo and IZA
}

\section{Discussion Paper No. 6665 June 2012}

\author{
IZA \\ P.O. Box 7240 \\ 53072 Bonn \\ Germany \\ Phone: +49-228-3894-0 \\ Fax: +49-228-3894-180 \\ E-mail: iza@iza.org
}

\begin{abstract}
Any opinions expressed here are those of the author(s) and not those of IZA. Research published in this series may include views on policy, but the institute itself takes no institutional policy positions.

The Institute for the Study of Labor (IZA) in Bonn is a local and virtual international research center and a place of communication between science, politics and business. IZA is an independent nonprofit organization supported by Deutsche Post Foundation. The center is associated with the University of Bonn and offers a stimulating research environment through its international network, workshops and conferences, data service, project support, research visits and doctoral program. IZA engages in (i) original and internationally competitive research in all fields of labor economics, (ii) development of policy concepts, and (iii) dissemination of research results and concepts to the interested public.
\end{abstract}

IZA Discussion Papers often represent preliminary work and are circulated to encourage discussion. Citation of such a paper should account for its provisional character. A revised version may be available directly from the author. 


\section{ABSTRACT}

\section{Migration, Redistribution and the Universal Welfare Model ${ }^{*}$}

The universal Scandinavian welfare model offers generous tax financed social benefits. The scheme is associated with workfare elements as a targeting device to direct benefits to those considered deserving. Thereby social insurance and egalitarian outcomes are achieved while work incentives and thus a high employment rate crucial for the financial viability of the model are maintained. The scope for this policy may depend critically on the characteristics of the population (abilities and preferences) and thus be significantly affected by immigration affecting the distribution of characteristics, especially if the model attracts immigrants with particular characteristics. The paper develops a simple model capable of capturing the rationale and essence of the above-mentioned redistribution model and considers its sensitivity and robustness to immigration, which may change the composition of the population in the ability and/or preference dimension.

JEL Classification: F22, J68, I31

Keywords: $\quad$ work incentives, active labour market policy, redistribution

Corresponding author:

Torben M. Andersen

School of Economics and Management

Department of Economics

University of Aarhus

8000 Aarhus C

Denmark

E-mail: tandersen@econ.au.dk

* Comments and suggestions from participants at the conference Globalization: Strategies and Effects, Koldingfjord 2011, are gratefully acknowledged. 


\section{Introduction}

Immigration is considered to be a particular threat to the universal or Scandinavian welfare model. The argument being that the tax financed collective redistribution and risk sharing arrangement is challenged by immigration of low skilled in particular. Moreover, it may even be argued that the model is a "magnet" for low skilled migrants, which tends to reinforce the problem.

The Scandinavian countries are characterised by high employment rates as well as a generous social safety net, but also high taxes. As a consequence there are no working poor ${ }^{1}$ and the income distribution is fairly equal by international standards. But the net gain from work is low, in particular for low income groups. Yet employment rates for these groups are rather high $^{2}$. The main reason is that the social safety net rests on a so-called "work model". On the one hand the scheme is universal and gives all the same rights, but on the other hand these rights are not unconditional. That is, the social safety net requires people to be actively searching for jobs, accepting appropriate jobs and willing to participate in various activation programmes (workfare) (see e.g. Andersen (2011)). It is not possible to passively claim benefits ${ }^{3}$. At the same time social and labour market policies are supposed to enhance qualifications to improve job finding possibilities. Given the distributional aims, it follows that the qualification requirements to find employment are high.

Moreover it is often asserted that a collective tax financed model with generous social benefits relies on strong work norms (see e.g. Lindbeck (1995)). Culture and norms are embedded in policies and institutions as well as economic behaviours. It is well known that the universal welfare model is characterized by a high labour force participation, in particular for women. This reflects gender and family values, and institutions and policies (e.g. child care) are set up so as to support a high labour force participation of both sexes. Such culture or norms may not be shared by immigrants as they often bring with them a different culture and norms from their home country, or ethnic identify, cf. Constant and Zimmermann (2008). Gender

\footnotetext{
${ }^{1}$ In e.g. Denmark no full-time employed are below the poverty line defined as $60 \%$ of the equivalized median income, Danish Council of Economic Advisors (2006).

${ }^{2}$ The employment rate for unskilled is higher in the Scandinavian countries than in e.g. the US despite a more compressed wage structure with higher minimum wages.

${ }^{3}$ The exception being schemes with a clear health condition like disability pension to which a gate-keeper mechanism is assigned to determine eligibility.
} 
role attitudes are particularly important for labour market outcomes (see e.g. Fortrin (2005)). It is well known that employment rates for immigrants from low income countries in general are lower than the average in host countries, in particular for women. Part of this difference may be explained by norms and attitudes beyond the effects of human capital and other factors of importance for employment (see e.g. Deding and Jacobsen (2008) and Constant et al. (2009)). Immigration may thus affect the viability of the welfare state by changing the distribution of characteristics of the population both with respect to abilities/qualifications and norms/attitudes/preferences. This may be crucial since the financial viability of the model rests on maintaining a high employment rate and since the distributional aims are to support those with low earnings ability

How can this model cope with immigration? What are the crucial characteristics of the composition of the population (and migrants) making it possible to sustain this model? The design issue in relation to migration is no different than the general issue of designing the social safety net. The key issue is targeting; that is, to ensure that social transfers are directed towards the "deserving" while leaving sufficient incentives for the "non-deserving" to be self-supporting via work. Two dimensions are particularly important in relation to work, namely, abilities and norms/preferences (value of leisure). Higher abilities imply a higher earnings potential in the labour market, and thus a larger chance of being self-supportive, and vice versa for people with low abilities. At the same time individuals with a high value of leisure ${ }^{4}$ are less likely to work if the combination of the tax and benefit scheme leaves a modest economic gain from work. However, if high able individuals with a high value of leisure decide not to work, the scope to support the less able weakens since tax revenue shrinks and social expenditures increase. The design issue is to ensure that this does not happen. Migration may challenge the scope for redistribution by changing the population structure in terms of the ability dimension (more low skilled) and in relation to preferences or norms regarding work (more with a high utility from leisure).

The fiscal burdens of immigration in the Scandinavian countries have been widely discussed. The background for this discussion is the fact that employment rates of immigrants from "low income" countries tend to be below average. In a generous tax financed welfare scheme, public finances are

\footnotetext{
${ }^{4}$ The formulation adopted allows preferences to be affected by norms since norms and their role for preferences are taken as given; they are equivalent.
} 
very sensitive to the employment rate (lower employment: less tax revenue and more expenditures), and therefore large-scale immigration may affect the financial viability of the welfare model. However, the consequences of migration depend both on the characteristics of migrants and the design of welfare schemes. Recent policy debates and initiatives in Scandinavia have thus been based on the view that the "activation" approach characterizing social and labour market policies can cope with the effect of immigration and serve to maintain a high employment rate, for Denmark see Regeringen (2011), and for Norway NOU (2011).

The following first considers under which conditions the "work model" succeeds in targeting social aid to the deserving, namely, the less able, while making the more able work and contribute to redistribution via tax payments. This allows an identification of the key properties ensuring that the "work model" maintains incentives to work and also allows more redistribution (higher benefits for those with a low earnings potential). This makes it possible to identify the characteristics of the population to which the model is most sensitive in relation to migration, and also whether migration may induce a regime shift.

Active labour market policies or workfare has a long tradition in the context of the Scandinavian welfare model. Workfare is also applied in other types of welfare models. In e.g. Anglo-Saxon countries workfare is considered as an add-on to improve the income of those working at low incomes (working poor). Seminal papers by Besley and Coate $(1992,1995)$ have analysed the role of workfare in income supplement/maintenance programmes. The idea is that the transfers can be better targeted to the deserving group if there is a workfare condition since that makes it less attractive to claim the supplement by those with higher earnings potential and thus a higher opportunity price of time (leisure). The setting is one where labour supply can vary along the intensive margin, and workfare crowds-out market work one-to-one via its time requirement. Transfers are proportional to the time spent in the programme activity. Besley and Coate $(1992,1995)$ show that inclusion of workfare conditions makes it possible to offer higher transfers to those with low earnings abilities, but in utility terms they are worse off. Workfare is never part of the optimal plan for a utilitarian policy maker. The reason is that the marginal utility value of the higher benefits falls short of the disutility from the workfare requirement. This ensures that the self-selection 
constraint for the highly able is fulfilled. Cuff (2000) extends ${ }^{5}$ this type of analysis to allow for heterogeneity across agents, not only in terms of abilities but also disutility from work. Under a Rawlsian criterion it is shown that workfare may be part of the optimal income supplement programme if the target group has low earnings ability and a low disutility from work. Note that in this model workfare also crowds out market work one-to-one, and it is assumed that the workfare requirements can be conditioned on the disutility from work, which differs across groups.

The present paper is related to the above work but differs in some crucial aspects. In the Scandinavian welfare model, workfare is not used as an income supplement device, working poor is not accepted, and the social safety net has universal eligibility and serves basic distributional goals. A key purpose of workfare is to ensure that transfers go to the target group only. Accordingly labour supply is considered along the extensive margin, and the social benefit is a universal right to all. The issue is how to design the social safety net at smallest costs, or for given costs such that it benefits the target group the most. The present paper focusses on the screening problem in targeting support to the deserving when agents differ both in abilities and preferences, and these characteristics are not observable. It is shown that it is possible to design workfare programmes which can both attain more redistribution (higher benefits) and improve the welfare/utility of benefit claimants. The key to this is to note that workfare policies do not necessarily have the same utility consequences across the population. In particular there may be a difference in how individuals with high earnings/abilities and those with low earnings/abilities evaluate the consequences of participating in specific workfare programmes. Hence, workfare may shift the self-selection constraint in a different way than it affects the utility of the target group. To focus on targeting, the workfare programme is assumed to be unproductive and costless to administer (or eventual costs are exactly covered by the productive outcome). While a special case it allows us to focus on the key reason why workfare can be a useful conditioning element in the social safety net. It is shown that in this context workfare may be part of the optimal policy both under a Rawlsian and a Utilitarian social welfare criterion.

The paper is organised as follows: Section 2 develops the model with

\footnotetext{
${ }^{5}$ Other extensions include productive workfare (Brett (1998)), unemployment insurance (Kreiner and Tranæs (2005)), moral hazard problems in job search (Andersen and Svarer (2012)) and shirking problems (Werding et.al. (2006)).
} 
agent heterogeneity in relation to both abilities and disutility from work in a setting with a tax financed social safety net offering a universal benefit to all who are not self-supporting. The role of employment conditionalities or workfare as an element in the social safety net is considered in Section 3 , while Section 4 considers the specific issue of how the welfare model is affected by immigration affecting the distribution of characteristics in the population, and whether parametric reforms or a regime change is needed in response to migration. Section 5 offers a few concluding remarks.

\section{Redistribution and workfare}

Assume that individuals of type $i$ have a utility function given as

$$
\Phi_{i}=U\left(c_{i}\right)+d_{i} V\left(1-h_{i}\right)
$$

where $c_{i}$ is consumption, $h_{i}$ working hours, and $1-h_{i}$ is leisure time (time endowment is normalized to one). The utility functions $U(\cdot)$ and $V(\cdot)$ are both increasing and concave with standard properties, and separability is assumed to simplify the analysis. Working hours $(h)$ when in job are assumed exogenous, and hence the only choice for an individual is whether to work or not $\left(h_{i}=0\right.$ or $\left.h_{i}=h\right)$; i.e. the extensive margin of labour supply.

Individuals differ along two dimensions, earnings ability and utility from leisure (disutility from work). Earnings ability ${ }^{6}$ may be either $a_{H}$ and $a_{L}$, $a_{H}>a_{L}=0$. Preferences for leisure are either $d_{H}$ or $d_{L}, d_{H}>d_{L}$. There are thus four possible types of individuals spanned by the earnings capability and disutility from work; i.e. $i \in I \equiv\{H H, H L, L L, L H\}$ where the first letter indicates productivity (high, low), and the last preferences for leisure (high, low). The distribution of the population according to abilities and preferences for leisure is:

\footnotetext{
${ }^{6}$ Setting the market wage of the $L$ type to zero simplifies the problem, but has no qualitative implications. The point is that the market income of the group is considered too low and that there is a political desire to increase the income of the group.
} 
Table 1: Characteristics and distribution of population

\begin{tabular}{|c|c|c|c|}
\hline & & Preference for leisure & \\
\hline & & $d_{L} \quad d_{H}$ & fraction \\
\hline Productivity & $\begin{array}{l}a_{H} \\
a_{L}\end{array}$ & $\begin{array}{ll}v_{H L} & v_{H H} \\
v_{L L} & v_{L H}\end{array}$ & $\begin{array}{l}\lambda \\
1-\lambda\end{array}$ \\
\hline & fraction & $1-\rho$ & \\
\hline
\end{tabular}

Where $v_{i}$ is the population share of type $i$, and $v_{H L}+v_{H H}+v_{L L}+v_{L H}=1$. A share of the population $\lambda(1-\lambda)$ has high (low) productivity, and a share $\rho(1-\rho)$ a low (high)preference for leisure.

High ability individuals in work obtain a market income $w_{H}=a_{H} h$, while the low ability individuals have no (a low) earnings ability in the market. The government offers a transfer (social assistance) $b$ to all without a market income (individual characteristics are non-observable), and finances it by a tax $T$ levied on those having market income. Eligibility for the benefit requires the recipient to spend $\alpha h$ hours in workfare activities, where $\alpha(0 \leq \alpha \leq 1)$ measures the activity requirement in time measured relative to working hours in normal jobs.

The redistribution problem is that the government wants to redistribute from those with a high ability to those with a low ability. That is, the benefit structure should be such that all the able work, while the unable (deserving) obtain a benefit. If all high ability individuals (share $\lambda$ ) work, the budget constraint for the government reads

$$
\lambda T=(1-\lambda) b
$$

The key question is how much redistribution that can be accomplished given that the policy maker cannot distinguish between the different types; i.e. the deserving (low earnings ability) and the non-deserving (high earnings ability). This is an issue of targeting or tagging (see Akerlof (1978)). The problem is that the high ability individuals with a high utility value of leisure time ( $H H$-type) may decide not to work and claim benefits, accepting less consumption but enjoying more leisure.

Individual characteristics are non-observable, and redistribution has to rely on observed market income. This restrains the scope for redistribution since if benefits are too generous, the $H H$-type decides not to work, which in turn reduces tax revenue and increases social expenditures. The extent of redistribution is thus restrained by the self-selection or incentive compatibility 
constraint ensuring that all high ability individuals work ${ }^{7}$. The question is whether this constraint can be lessened by attaching conditions to receiving benefits (workfare), $\alpha>0$. Clearly such a condition makes it less attractive for the $H H$-type to claim benefits, but at the same time it also demands time from the beneficiaries, and it is not a priori clear that they are better off (Besley and Coate $(1992,1995))$.

To answer these questions, we first have to work out how the self-selection condition for the $\mathrm{HH}$-type affects the scope for redistribution. Note first that disposable income for the $\mathrm{HH}$ - type is

$$
y_{H H}=\left\{\begin{array}{l}
w_{H}-T \text { if working } \\
b \text { if not working }
\end{array}\right.
$$

The $H H$-type decides not to work if

$$
U(b)+d_{H} V(1-\alpha h) \geq U\left(w_{H}-T\right)+d_{H} V(1-h)
$$

This implies that there is a maximal benefit level $\widehat{b}$ which can be offered and still have the $\mathrm{HH}-$ type working. It is given by the condition

$$
U(\widehat{b})+d_{H} V(1-\alpha h)=U\left(w_{H}-\frac{1-\lambda}{\lambda} \widehat{b}\right)+d_{H} V(1-h)
$$

and it can be summarized by the implicit function

$$
\widehat{b}=\widehat{b}\left(\alpha, \lambda, w_{H}, d_{H}, h\right)
$$

It is implied that the self-selection constraint is fulfilled if $b \leq \widehat{b}$.

To illustrate this, consider the case of linear utility ${ }^{8}$ in which case the maximal benefit is given by $\widehat{b}=\lambda\left[w_{H}+d_{H}(\alpha-1) h\right]$.

A workfare requirement attached to the benefit eligibility conditions increases the maximal benefit level since

$$
\frac{\partial \widehat{b}}{\partial \alpha}=\frac{d_{H} V^{\prime}(1-a h) h}{\frac{1-\lambda}{\lambda} U^{\prime}\left(w_{H}-\frac{1-\lambda \widehat{b})+U^{\prime}(\widehat{b})}{\lambda}\right.}>0
$$

\footnotetext{
${ }^{7}$ This is not always to the benefit of the $L L$-types. This is the case if the population share of the $H H$-type is sufficiently high, cf. Appendix $C$. This is implicitly assumed in the following.

${ }^{8}$ Let utility be $\Phi_{i}=c_{i}-d_{i}[1-h]$.
} 
i.e. the more time demanding the work requirement $(\alpha)$, the larger the maximal benefit level $(\widehat{b})$ can be. The intuition is that the work requirement makes it less attractive for the $H H$-type to pretend to have a low ability. That is, a given incentive structure ensuring that all the $H H$-types work can be maintained by offering either low benefits with low (no) activity requirements or high benefits with high activity requirements. This can also be phrased in the sense that it is easier to redistribute income (target benefits) if there is a workfare conditionality in the benefit scheme. Note also that the larger the share of highly able $(\lambda)$, the more can benefits be increased by increasing the workfare requirement ${ }^{9}$; i.e. $\frac{\partial}{\partial \lambda}\left(\frac{\partial \widehat{b}}{\partial \alpha}\right)>0$.

For later reference note also that a higher fraction of high ability individuals $(\lambda)$ increases the maximal benefit level $(\widehat{b})$ :

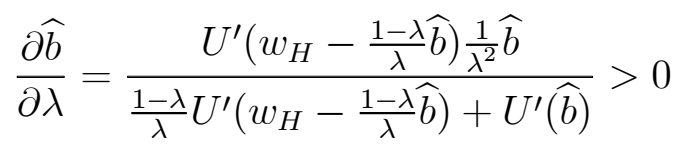

This basically arises via the budget effect due to more high able tax-payers and fewer less able benefit recipients ${ }^{10}$.

\section{Welfare consequences of workfare conditions}

The above shows that by attaching workfare requirements to the redistribution scheme, it becomes possible to offer a higher maximal benefit level. This is to the immediate benefit of the low ability types receiving the benefit, but it also comes at the cost of the participation requirement. It is thus not a priori obvious whether the target group is better off in utility terms.

\footnotetext{
${ }^{9}$ We have $\frac{\partial}{\partial \lambda}\left(\frac{\partial \widehat{b}}{\partial \alpha}\right)=\frac{-d_{H} V^{\prime}(1-a h) h}{\left[\frac{1-\lambda}{\lambda} U^{\prime}\left(w_{H}-\frac{1-\lambda}{\lambda} \widehat{b}\right)+U^{\prime}(\widehat{b})\right]^{2}}\left[\frac{-1}{\lambda^{2}} U^{\prime}\left(w_{H}-\frac{1-\lambda}{\lambda} \widehat{b}\right)+\frac{1-\lambda}{\lambda} \frac{1}{\lambda^{2}} U^{\prime \prime}\left(w_{H}-\frac{1-\lambda}{\lambda} \widehat{b}\right)\right]>0$.

${ }^{10}$ Note that $\frac{\partial \widehat{b}}{\partial \lambda} \frac{\lambda}{\widehat{b}}=\frac{1}{1-\lambda} \frac{\frac{1-\lambda}{\lambda} U^{\prime}\left(w_{H}-\frac{1-\lambda}{\lambda} \widehat{b}\right)}{\frac{1-\lambda}{\lambda} U^{\prime}\left(w_{H}-\frac{1-\lambda}{\lambda} \widehat{b}\right)+U^{\prime}(\widehat{b})}=\frac{U^{\prime}\left(w_{H}-\frac{1-\lambda}{\lambda} \widehat{b}\right)}{(1-\lambda) U^{\prime}\left(w_{H}-\frac{1-\lambda}{\lambda} \widehat{b}\right)+\lambda U^{\prime}(\widehat{b})}<1$ for all $\lambda \in[0,1]$.
} 
For any benefit package $(b, \alpha)$ the low ability individuals with a low value of leisure (the $L L$-type) are always worse off than those with a high utility from leisure (the $L H$-type); i.e.

$$
U(b)+d_{L} V(1-a h)<U(b)+d_{H} V(1-a h) \quad \text { for all } b>0, \alpha \in[0,1]
$$

The least well-off in society are thus those with a low ability and a low value of leisure ( $L L$-type). Consider next the utility this group obtains if they are offered the maximal benefit $\widehat{b}(\cdot)$ for a given level of the activation requirement $(\alpha)$. Utility for the $L L-t y p e$ is

$$
U(\widehat{b}(\cdot))+d_{L} V(1-a h)
$$

Consider next the utility effect of a change in the workfare requirement accompanied by a change in the benefit level, cf. (2), we have

$$
\begin{aligned}
\frac{\partial\left[U(\widehat{b}(\cdot))+d_{L} V(1-a h)\right]}{\partial \alpha} & =U^{\prime}(\widehat{b}(\cdot)) \frac{\partial \widehat{b}(\cdot)}{\partial \alpha}-V^{\prime}(1-a h) d_{L} h \\
& =\frac{U^{\prime}(\widehat{b}) V^{\prime}(1-a h) d_{H} h}{\frac{1-\lambda}{\lambda} U^{\prime}\left(w-\frac{1-\lambda}{\lambda} \widehat{b}\right)+U^{\prime}(\widehat{b})}-V^{\prime}(1-a h) d_{L} h
\end{aligned}
$$

Consider for a moment the special case where all have the same utility value from leisure $\left(d_{H}=d_{L}\right)$. In this case the low ability type is unambiguously worse off since

$$
\begin{aligned}
\frac{\partial\left[U(\widehat{b}(\cdot))+d_{L} V(1-a h)\right]}{\partial \alpha} & =\left[\frac{U^{\prime}(\widehat{b})}{\frac{1-\lambda}{\lambda} U^{\prime}\left(w-\frac{1-\lambda}{\lambda} \widehat{b}\right)+U^{\prime}(\widehat{b})}-1\right] V^{\prime}(1-a h) d_{L} h \\
& <0 \text { for } d_{H}=d_{L}
\end{aligned}
$$

This is effectively a restatement of the Besley and Coates $(1992,1995)$ result, though here shown for labour supply choices along the extensive margin. The intuition for this result is seen by noting that the marginal rate of substitution between benefits and work requirements for the $L L$-type is

$$
\left.\frac{\widehat{d b}}{d \alpha}\right|_{L L}=\frac{V^{\prime}(1-a h) d_{L} h}{U^{\prime}(\widehat{b})}
$$


but at the self-selection constraint determined by the preferences of the $\mathrm{HH}$ type it is

$$
\left.\frac{\partial \widehat{b}}{\partial \alpha}\right|_{S S}=\frac{d_{H} V^{\prime}(1-a h) h}{\frac{1-\lambda}{\lambda} U^{\prime}\left(w-\frac{1-\lambda}{\lambda} \widehat{b}\right)+U^{\prime}(\widehat{b})}
$$

and for $d_{H}=d_{L}$ we have unambiguously that

$$
\left.\frac{\partial \widehat{b}}{\partial \alpha}\right|_{S S}<\left.\frac{\widehat{d b}}{d \alpha}\right|_{L L}
$$

That is, the higher benefit that can be offered in return for a higher activity requirement along the self-selection constraint for the $H H$-type is lower than the one required by the $L L$-type to be at least as well-off. The reason for this difference is the tax increase implied by higher taxes. Hence, in utility terms the $L L$-type is worse off when benefits are conditional rather than unconditional. Introduction of the workfare conditionality does not make it easier to achieve the distributional goals when all have the same utility from leisure. Notice that there is an important difference depending on whether the two schemes are compared in terms of benefits/income or utility. In terms of income, the $L L$-type is better off with the conditionality, but not in utility terms due to the activity requirement (Besley and Coate $(1992,1995)$ ).

Returning to the general case $\left(d_{H}>d_{L}\right)$, we have that a change in the workfare requirement affects the utility for the $L L$-type by

$$
\frac{\partial\left[U(\widehat{b}(\cdot))+d_{L} V(1-a h)\right]}{\partial \alpha}=\left[\frac{U^{\prime}(\widehat{b})}{\frac{1-\lambda}{\lambda} U^{\prime}\left(w_{H}-\frac{1-\lambda}{\lambda} \widehat{b}\right)+U^{\prime}(\widehat{b})}-\frac{d_{L}}{d_{H}}\right] d_{H} V_{l}((1-a h)) h \lesseqgtr 0
$$

We thus have that the $L L$-type is better off when the redistribution scheme includes workfare; i.e.

$$
\left.\frac{\partial\left[U(\widehat{b}(\cdot))+d_{L} V(1-a h)\right]}{\partial \alpha}\right|_{\alpha=0}>0
$$

if (necessary and sufficient condition)

$$
\frac{d_{H}}{d_{L}}>\frac{1-\lambda}{\lambda} \frac{U^{\prime}\left(w_{H}-\frac{1-\lambda}{\lambda} \widehat{b}(0)\right)}{U^{\prime}(\widehat{b}(0))}+1>1
$$


Note that the condition holds for $\lambda=1$. The following assumption is sufficient to ensure that there exists a non-trivial interval in which workfare is part of the benefit package.

Assumption: $U^{\prime}(\widehat{b}(\cdot)) \frac{\partial \widehat{b}(\cdot)}{\partial \alpha}$ is increasing in $\lambda$.

The assumption implies that the direct effect of a change in the share of highly able $(\lambda)$ allowing a higher benefit increase from an increase in the workfare requirement dominates the indirect effect that a higher benefit reduces the marginal utility of consumption for benefit recipients.

Under the assumption made above it follows that the RHS of (7) is decreasing in $\lambda$ (see Appendix $A$ ), and it follows that there exists a $\widetilde{\lambda}^{R}<1$ such that a workfare condition $(\alpha>0)$ is part of the optimal benefit package under a Rawlsian welfare criterion for $\widetilde{\lambda}^{R}<\lambda \leq 1$. For the special case where the marginal utility of consumption is constant $\left(U^{\prime}(y)=c\right.$ for all $\left.y\right)$, we have that ${ }^{11} \widetilde{\lambda}^{R}=\frac{d_{L}}{d_{H}}$. The intuition why workfare is only optimal when the share of able workers $(\lambda)$ is high derives from the budget constraint. With a high share of able workers, the tax burden of financing a high benefit is small, and this would other things being equal allow a high benefit level. However, this would create an incentive for the $H H$-type to stop working and start claiming benefits. By attaching the workfare requirement to the benefit scheme, the self-selection constraint remains satisfied despite the high benefit level.

For $\widetilde{\lambda}^{R}<\lambda \leq 1$ the optimal benefit package $\left(\widehat{b}\left(\alpha^{*}\right), \alpha^{*}\right)$ is determined by

$$
\frac{U^{\prime}(\widehat{b})}{\frac{1-\lambda}{\lambda} U^{\prime}\left(w_{H}-\frac{1-\lambda}{\lambda} \widehat{b}\right)+U^{\prime}(\widehat{b})}=\frac{d_{L}}{d_{H}}
$$

In appendix $A$ it is shown that an increase in $\lambda$ unambiguously leads to an increase in the benefit level, and for $\tilde{\lambda}^{R}<\lambda \leq 1$ the workfare requirement is also increasing in $\lambda$.

Observe that the low ability type with a high value from leisure (the $L H-$ type) is always worse off ${ }^{12}$ when workfare requirements are associated

\footnotetext{
${ }^{11}$ In this case $\frac{\partial\left[\hat{b}(\alpha)+d_{L}[1-a h]\right]}{\partial \alpha}=\left[\lambda d_{H}-d_{L}\right] h \lesseqgtr 0$ for $\lambda \gtreqless \frac{d_{L}}{d_{H}}<1$. Hence, the linear case has a bang-bang form with no workfare for $\lambda<\frac{d_{L}}{d_{H}}$ and full workfare $(\alpha=1)$ for $\lambda>\frac{d_{L}}{d_{H}}$.

${ }^{12}$ But they are still better off than the $L L$-type.
} 
with the redistribution scheme since

$$
\begin{aligned}
& \frac{\partial\left[U(\widehat{b}(\cdot))+d_{H} V(1-a h)\right]}{\partial \alpha} \\
= & {\left[\frac{U^{\prime}(\widehat{b})}{\frac{1-\lambda}{\lambda} U^{\prime}\left(w_{H}-\frac{1-\lambda}{\lambda} \widehat{b}\right)+U^{\prime}(\widehat{b})}-1\right] d_{H} V^{\prime}(1-a h) h<0 . }
\end{aligned}
$$

The high ability types $(H H$ and $H L)$ are worse off since higher benefits lead to higher taxes, but the self-selection constraint is fulfilled via the more demanding workfare requirement.

It follows under a Rawlsian criterion that workfare conditions should be attached to the redistribution scheme if $\tilde{\lambda}^{R}<\lambda \leq 1$. This is noteworthy since under the Rawlsian criterion the concern is the utility of the least well-off, and they are facing the ordeal of having to participate in the workfare programme to remain eligible for the transfer. However, the workfare condition makes it possible to offer a higher benefit level; that is, the screening constraint is shifted in such a way that they are better off not only in terms of income and consumption but also in utility terms.

Two further comments are in order. The first is that activation serves to make all highly able work. It is sometimes argued that workfare policies rely on the notion that the "poor are lazy". The present analysis shows that this is not the case. The problem is "lazy people with high abilities" - the $H H$-type - which makes it more difficult to target the deserving (the $L L$ type). The problem is not that some low ability individuals may have a high value of leisure, the problem is that some high ability individuals have a high utility from leisure! Secondly, the workfare activity considered here is not productive and it has no direct effect on employment possibilities; it serves a screening purpose only. Even though workfare is critical for the employment rate in the sense of ensuring that all able work, it is implied that an empirical analysis of how the workfare activity has affected employability, wages and productivity directly will find no effect, and yet the policy is very effective. As any screening mechanism it has the feature that it ends up harming the "wrong" group in the sense that when the self-selection constraint is met, the highly able work and the low ability individuals are required to participate in workfare programmes to be eligible for benefits. The screening paradox applies, that is, the burden does not fall on the group causing the problem, but on those considered deserving of help. 
Alternative to the Rawlsian approach taken above, it may be questioned whether workfare is part of the optimal policy under a standard Utilitarian social welfare function. As noted in the introduction, the literature on workfare as part of income supplement programmes finds that workfare is not part of the optimal package under a Utilitarian approach. However, the heterogeneity of the population may change this, as shown in the following.

Under a utilitarian criterion the social welfare function reads

$$
\begin{aligned}
\Delta= & \left.\left.v_{H H}\left[U\left(w_{H}-T\right)+d_{H} V(1-h)\right)\right]+v_{H L}\left[U\left(w_{H}-T\right)+d_{L} V(1-h)\right)\right] \\
& \left.+v_{L H}\left[U(b)+d_{H} V(1-\alpha h)\right)\right]+v_{L L}\left[U\left(b+d_{L} V(1-\alpha h)\right)\right]
\end{aligned}
$$

and it should be maximized under the self-selection constraint, implying that the benefit level offered the non-working should satisfy

$$
b \leq \widehat{b}\left(\alpha, \lambda, w_{H}, d_{H}, h\right)
$$

It is shown in the appendix that $\alpha>0$ provided that

$$
\frac{U^{\prime}(\widehat{b}(0))-U^{\prime}\left(w_{H}-\frac{1-\lambda}{\lambda} \widehat{b}\left(0, \lambda, w_{H}, d_{H}, h\right)\right)}{U^{\prime}\left(w_{H}-\frac{1-\lambda}{\lambda} \widehat{b}\left(0, \lambda, w_{H}, d_{H}, h\right)\right)}>\left[\frac{1-\lambda}{v_{L L}} \frac{d_{H}}{d_{H}-d_{L}}-1\right] \frac{1}{\lambda}
$$

The above gives a necessary condition for introduction of workfare to increase social welfare under a Utilitarian criterion. Notice that the key to this result is that the marginal rate of substitution between the $L L$-type gaining from higher benefits allowed by workfare may be higher than the marginal rate of substitution for the $H H$-type crucial for the targeting (self-selection constraint); i.e.

$$
\begin{aligned}
\frac{d \widehat{b}}{d \alpha} & \mid \quad L L=\frac{V^{\prime}(1-a h) d_{L} h}{U^{\prime}\left(\widehat{b}\left(0, \lambda, w_{H}, d_{H}, h\right)\right)} \\
& <\frac{d_{H} V^{\prime}(1-a h) h}{\frac{1-\lambda}{\lambda} U^{\prime}\left(w-\frac{1-\lambda}{\lambda} \widehat{b}\left(0, \lambda, w_{H}, d_{H}, h\right)\right)+U^{\prime}\left(\widehat{b}\left(0, \lambda, w_{H}, d_{H}, h\right)\right)}=\left.\frac{\partial \widehat{b}}{\partial \alpha}\right|_{S S}
\end{aligned}
$$

Hence, even under a traditional utilitarian criterion it may be possible to justify inclusion of workfare elements in a redistribution scheme. 


\section{Migration}

It has been argued that the welfare state is a magnet attracting in particular low skilled workers, but also creating incentives for high skilled to migrate (Borjas(1999)). The reason is that the welfare state redistributes from the highly skilled to the low skilled, and hence the former are net contributors and the latter net-beneficiaries from the scheme. It is an open question empirically whether welfare states are magnets (see Pedersen et al. (2008), Giuelietti et al. (2011)). However, the migration flows are also affected by migration rules, and Razin and Wahba (2011) argue that welfare states tend to design migration rules to attract skilled workers.

The following considers the issue of migration in two steps. Irrespective of the motives and causes underlying immigration, it has consequences if it changes the population characteristics. In addition the design of the welfare state may have an effect on the types of people immigrating (and emigrating) to the society. These considerations also bring insights into the characteristics which may be important in designing immigration rules.

Migration affects the scope for redistribution only if it changes the distribution of population characteristics. A scaling up or down of the population size for a given distribution will have no consequences. The question is whether the scope for redistribution is more sensitive to abilities or preferences for leisure.

Consider the implications of migration in the Rawlsian case, that is, the benefit package $(b, \alpha)$ is determined so as to maximize the utility of the least well-off in society; i.e. the activation requirement is determined from the condition

$$
\frac{U^{\prime}(\widehat{b}(\cdot))}{\frac{1-\lambda}{\lambda} U^{\prime}\left(w_{H}-\frac{1-\lambda}{\lambda} \widehat{b}(\cdot)\right)+U^{\prime}(\widehat{b}(\cdot))}=\frac{d_{L}}{d_{H}}
$$

There is an interior solution $\alpha \in[0,1]$ if $\tilde{\lambda}^{R}<\lambda \leq 1$, if not we have $\alpha=0$ and $b=\widehat{b}\left(0, \lambda, d_{H}, h\right)$. The outcome is illustrated in the figure below ${ }^{13}$.

\footnotetext{
${ }^{13}$ For simplicity the curves are drawn linear.
} 
Figure 1: Optimal benefit package and population structure



Several observations on the implications of migration are in order. First, the only dimension of the population characteristic which matters is the share of able $(\lambda)$. The share of individuals with high or low preferences for leisure does not matter. This is so for two reasons. The targeting problem is to ensure that all highly able are working, and if this is ensured, the share with a high preference for leisure does not matter. The Rawlsian criterion implies that only the preference of the $H H$-type matters, and not the share of low able individuals with a high or low preference for leisure (irrespective of preferences for leisure, individuals with low abilities cannot find a job).

If $\lambda>\tilde{\lambda}^{R}$, we are in an activation regime; that is, benefits are high but are associated with a workfare requirement. We also see that the larger the share of highly able, the higher both the benefit and the activation requirement. The intuition is that a larger share of highly able allows a higher benefit level which increases the incentive of the high able with a strong preference for leisure not to work, and therefore a strengthening of the workfare requirement is needed to meet the self-selection constraint for the $\mathrm{HH}$-type. The model thus has the empirical prediction that societies with a high share of 
highly able should also have higher benefit generosity as well as a stronger focus on activation requirements. Features which seem to characterize the Scandinavian countries rather well.

If migration reduces the share of highly able in society ( $\lambda$ decreases), we have that both benefit levels and activation requirements are reduced (parameter reform). Moreover, if the share with high abilities falls below the critical level $\tilde{\lambda}^{R}$, we have that benefits are lowered even more, and the activation requirement is given up (regime change). Note that it in either case is implied that the utility of a single $L L$-type decreases.

How would the redistribution scheme affect the incentive to migrate? Clearly, the activation regime offers higher utility to the $L L$-type and thus a stronger incentive for individuals with these characteristics to enter the country. Oppositely, the $L H$-type is worse off and has a less strong incentive to immigrate. The universal welfare model with its activation regime is thus particularly attractive to individuals with a high preference for leisure. However, as noted above the share of individuals with high or low preferences for leisure is not critical, the share of highly able is. The system thus tends to be an attractor for individuals with low abilities, and the opposite for individuals with high abilities.

\section{Concluding remarks}

The scope for redistribution depends on population characteristics and may thus be affected by migration. In countries with extended welfare states, it has in particular been a concern whether a generous welfare state can be maintained while still ensuring that a large proportion of the population is in employment. This is a problem of targeting, and workfare policies in the broad sense of employment conditionalities in the social safety net have played a crucial role in this respect. It is also politically perceived that workfare policies can be used to cope with the challenges raised by immigration.

Yet, the welfare rationale for workfare policies has been questioned in the literature. This paper has shown why workfare is an important element of a redistribution policy when individuals differ in terms of both productivity (ability) and preferences for leisure (work norms). Workfare allows a better targeting and ensures that the least well-off end up in a better situation. Although they have to participate in the workfare activities, they benefit 
from the higher benefits which can be offered. Also under a Utilitarian social welfare function it may be possible to justify workfare policies. This analysis also points to the distribution of productivity to be crucial for the extent and form of redistribution, while the distribution of preferences with respect to leisure (work norms) is of no direct importance. This also implies that immigration changing the distribution of productivities is important, while the implications for the distribution of preferences are not.

If migration reduces the share of highly able in society, it follows that both benefit levels and activation requirements are reduced (parameter reform). Moreover, if the share falls below a critical level, we have that benefits are lowered even more, and the activation requirement is given up (regime change).

\section{References}

Akerlof, G.A., 1978, The Economics of "Tagging" as Applied to the Optimal Income Tax, Welfare Programs and Manpower Planning, American Economic Review, 68, 8-19.

Andersen, T.M., 2011, Why do Scandinavians Work? Working Paper

Andersen, T.M., and M. Svarer, 2012, The role of workfare in striking a balance between incentives and insurance in the labour market, Economica, to appear.

Besley, T., and S. Coate, 1992, Workfare versus Welfare: Incentive Arguments for Work Requirements in Poverty-Alleviation Programs, American Economic Review, 82(1), 249-61.

Betts, C., 1998, Who Should be on Workfare? The Use of Work Requirements as Part of an Optimal Tax Mix, Oxford Economic Papers, 50, 607-22.

Besley, T., and S. Coate, 1995, The Design of Income Maintenance Programmes, Review of Economic Studies, 62, 187-221.

Borjas, G. J, 1999, Immigration and Welfare Magnets, Journal of Labor Economics, 17(4), 607-37.

Cuff, K., 2000, Optimality of Workfare with Heterogenous Preferences, Canadian Journal of Economics, 33(1), 149-74.

Constant, A.F., M. Kahanec, U. Rinne, and K.F. Zimmermann, 2009, Ethnicity, Job Search and Labor Market Reintegration of the Unemployed, International Journal of Manpower, 2011, 32 (7), 753-776

Constant, A.F., Klaus F. Zimmermann, 2008, Measuring Ethnic Identity and Its Impact on Economic Behavior, Journal of the European Economic 
Association, 2008, 6 (2-3), 424-433.

Danish Economic Council, 2006, The Danish Economy, Copenhagen.

Deding, M., and V. Jacobsen, 2008, Employment among immigrant women and men in Denmark - The role of attitudes, Working Paper, 2008-8, The Danish National Center for Social Research.

Fortrin, N.M., 2005, Gender role attitudes and labour market outcomes of women across OECD countries, Oxford Economic Policy Review 21(3), 416-438.

Giuelietti, C., M. Guzi, M. Kahanec, and K. Zimmermann, 2011, Unemployment Benefits and Immigration: Evidence from the EU, IZA Working Paper.

Holzner, C., V. Meier and M. Werding, 2010, Workfare, Monitoring and Efficiency Wages, Journal of Macroeconomics, 32, 157-168.

Lindbeck, A., 1995, Hazardous Welfare State Dynamics, American Economic Review, Papers and Proceedings, May 1995, 9-15.

Kreiner, C.T., and T. Tranæs, 2005, Optimal Workfare with Voluntary and Involuntary Unemployment, Scandinavian Journal of Economics, 107 (3), 459-474.

Pedersen, P.J,. M. Pytlikova, and N. Smith, 2008, Selection and Network Effects: Migration Flows into OECD Countries 1990-2000, European Economic Review, 52(7), 1160-1186.

Razin, A. and J. Wahba, 2011, Welfare Magnet Hypothesis, Fiscal Burden and Immigration Skill Selectivity, NBER Working Paper 17515.

\section{Appendix A: Comparative Static Results}

We have that the first order condition for the choice of $\alpha$ maximizing the utility of the $L L$-type is given as

$$
\begin{aligned}
\Gamma(\alpha, \lambda) & \equiv \frac{\partial\left[U(\widehat{b}(\cdot))+d_{L} V(1-a h)\right]}{\partial \alpha} \\
& =\left[\frac{U^{\prime}(\widehat{b})}{\frac{1-\lambda}{\lambda} U^{\prime}\left(w_{H}-\frac{1-\lambda}{\lambda} \widehat{b}\right)+U^{\prime}(\widehat{b})}-\frac{d_{L}}{d_{H}}\right] d_{H} V_{l}(1-a h) h=0
\end{aligned}
$$

The second order condition is

$$
\Gamma_{\alpha}(\alpha, \lambda)<0
$$


We have that $\left(y \equiv w_{H}-\frac{1-\lambda}{\lambda} \widehat{b}\right)$

$$
\begin{aligned}
\Gamma_{\alpha}(\alpha, \lambda) & =\frac{U^{\prime \prime}(\widehat{b}) \frac{\partial \widehat{b}(\cdot)}{\partial \alpha}\left[\frac{1-\lambda}{\lambda} U^{\prime}(y)+U^{\prime}(\widehat{b})\right]-U^{\prime}(\widehat{b})\left[U^{\prime \prime}(\widehat{b}) \frac{\partial \widehat{b}(\cdot)}{\partial \alpha}-\left(\frac{1-\lambda}{\lambda}\right)^{2} U^{\prime \prime}(y) \frac{\partial \widehat{b}(\cdot)}{\partial \alpha}\right]}{\left[\frac{1-\lambda}{\lambda} U^{\prime}(y)+U^{\prime}(\widehat{b})\right]^{2}} \\
& =\frac{U^{\prime \prime}(\widehat{b}) \frac{1-\lambda}{\lambda} U^{\prime}(y)+U^{\prime}(\widehat{b})\left(\frac{1-\lambda}{\lambda}\right)^{2} U^{\prime \prime}(y)}{\left[\frac{1-\lambda}{\lambda} U^{\prime}(y)+U^{\prime}(\widehat{b})\right]^{2}(\cdot)} \frac{\partial}{\partial \alpha}<0
\end{aligned}
$$

Hence the second order condition is always fulfilled.

It follows that

$$
\frac{d \alpha}{d \lambda}=-\frac{\Gamma_{\lambda}(\alpha, \lambda)}{\Gamma_{\alpha}(\alpha, \lambda)}
$$

and hence

$$
\operatorname{sign}\left[\frac{d \alpha}{d \lambda}\right]=\operatorname{sign}\left[\Gamma_{\lambda}(\alpha, \lambda)\right]
$$

We have that

$$
\begin{aligned}
\Gamma(\alpha, \lambda) & \left.=\left[U^{\prime} \widehat{b}\right) \frac{\partial \widehat{b}(\cdot)}{\partial \alpha}-\frac{d_{L}}{d_{H}}\right] d_{H} V_{l}((1-a h)) h \\
& =\left[\frac{U^{\prime}(\widehat{b})}{\frac{1-\lambda}{\lambda} U^{\prime}\left(w_{H}-\frac{1-\lambda}{\lambda} \widehat{b}\right)+U^{\prime}(\widehat{b})}-\frac{d_{L}}{d_{H}}\right] d_{H} V_{l}((1-a h)) h=0
\end{aligned}
$$

Hence the assumption that $U^{\prime}(\widehat{b}) \frac{\partial \widehat{b}(\cdot)}{\partial \alpha}$ is increasing in $\lambda$ ensures that $\Gamma_{\lambda}>0$, and hence $\frac{d \alpha}{d \lambda}>0$. We have

$\Gamma_{\lambda}(\alpha, \lambda)=\frac{\frac{\partial b}{\partial \lambda}\left[U^{\prime \prime}(b) \frac{1-\lambda}{\lambda} U^{\prime}(y)+\left(\frac{1-\lambda}{\lambda}\right)^{2} U^{\prime \prime}(y) U^{\prime}(\widehat{b})\right]-U^{\prime}(\widehat{b})\left[-\frac{1}{\lambda^{2}} U^{\prime}(y)+\frac{1-\lambda}{\lambda} U^{\prime \prime}(y) \frac{b}{\lambda^{2}}\right]}{\left[\frac{1-\lambda}{\lambda} U^{\prime}\left(w_{H}-\frac{1-\lambda}{\lambda} \widehat{b}\right)+U^{\prime}(\widehat{b})\right]^{2}}$

Hence the condition that $U^{\prime}(\widehat{b}) \frac{\partial \widehat{b}(\cdot)}{\partial \alpha}$ is increasing in $\lambda$ can be written

$\frac{\partial b}{\partial \lambda}\left[U^{\prime \prime}(b) \frac{1-\lambda}{\lambda} U^{\prime}(y)+\left(\frac{1-\lambda}{\lambda}\right)^{2} U^{\prime \prime}(y) U^{\prime}(\widehat{b})\right]>U^{\prime}(\widehat{b})\left[-\frac{1}{\lambda^{2}} U^{\prime}(y)+\frac{1-\lambda}{\lambda} U^{\prime \prime}(y) \frac{b}{\lambda^{2}}\right]$ 
or

$$
\begin{aligned}
& \frac{\partial b}{\partial \lambda}<\frac{U^{\prime}(\widehat{b})\left[-\frac{1}{\lambda^{2}} U^{\prime}(y)+\frac{1-\lambda}{\lambda} U^{\prime \prime}(y) \frac{b}{\lambda^{2}}\right]}{U^{\prime \prime}(b) \frac{1-\lambda}{\lambda} U^{\prime}(y)+\left(\frac{1-\lambda}{\lambda}\right)^{2} U^{\prime \prime}(y) U^{\prime}(\widehat{b})} 0
\end{aligned}
$$

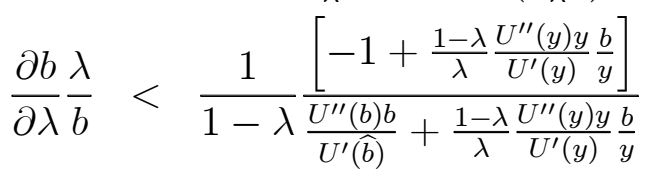

Defining $\Phi(y) \equiv-\frac{U^{\prime \prime}(y) y}{U^{\prime}(y)}$ and $\Phi(b) \equiv-\frac{U^{\prime \prime}(b) b}{U^{\prime}(\hat{b})}$ the condition can be rewritten

$$
\frac{\partial b}{\partial \lambda} \frac{\lambda}{b}<\frac{1}{1-\lambda} \frac{\left[\lambda+(1-\lambda) \Phi(y) \frac{b}{y}\right]}{\lambda \Phi(b)+(1-\lambda) \Phi(y) \frac{b}{y}}
$$

From (4) we have

$$
\frac{\partial \widehat{b}(\cdot)}{\partial \lambda} \frac{\lambda}{b}=\frac{1}{1-\lambda} \frac{\frac{1-\lambda}{\lambda} U^{\prime}\left(w-\frac{1-\lambda}{\lambda} \widehat{b}\right)}{\frac{1-\lambda}{\lambda} U^{\prime}\left(w-\frac{1-\lambda}{\lambda} \widehat{b}\right)+U^{\prime}(\widehat{b})}=\frac{1}{1-\lambda}\left[1-\frac{d_{L}}{d_{H}}\right]
$$

Hence the condition is

$$
1-\frac{d_{L}}{d_{H}}<\frac{\left[\lambda+(1-\lambda) \Phi(y) \frac{b}{y}\right]}{\lambda \Phi(b)+(1-\lambda) \Phi(y) \frac{b}{y}}
$$

Turning to the effect of a change in the share of highly able on the benefit level, we have

$$
\frac{d b}{d \lambda}=b_{\alpha} \frac{d \alpha}{d \lambda}+b_{\lambda}
$$

Inserting from above, it follows that

$$
\begin{aligned}
\frac{d b}{d \lambda} & =-\frac{\frac{\partial b}{\partial \lambda}\left[U^{\prime \prime}(b) \frac{1-\lambda}{\lambda} U^{\prime}(y)+\left(\frac{1-\lambda}{\lambda}\right)^{2} U^{\prime \prime}(y) U^{\prime}(\widehat{b})\right]-U^{\prime}(\widehat{b})\left[\frac{1-\lambda}{\lambda} U^{\prime \prime}(y) \frac{b}{\lambda^{2}}-\frac{1}{\lambda^{2}} U^{\prime}(y)\right]}{\left[U^{\prime \prime}(\widehat{b}) \frac{1-\lambda}{\lambda} U^{\prime}(y)+U^{\prime}(\widehat{b})\left(\frac{1-\lambda}{\lambda}\right)^{2} U^{\prime \prime}(y)\right]}+\frac{\partial b}{\partial \lambda} \\
& =\frac{U^{\prime}(\widehat{b})\left[-\frac{1}{\lambda^{2}} U^{\prime}(y)+\frac{1-\lambda}{\lambda} U^{\prime \prime}(y) \frac{b}{\lambda^{2}}\right]}{\left[U^{\prime \prime}(\widehat{b}) \frac{1-\lambda}{\lambda} U^{\prime}(y)+U^{\prime}(\widehat{b})\left(\frac{1-\lambda}{\lambda}\right)^{2} U^{\prime \prime}(y)\right]}>0
\end{aligned}
$$




\section{Appendix B: Workfare under a utilitarian social welfare function}

Consider the utilitarian welfare function

$$
\begin{aligned}
\Delta= & v_{H H}\left[U\left(w_{H}-\frac{1-\lambda}{\lambda} b\right)+d_{H} V(1-h)\right]+v_{H L}\left[U\left(w_{H}-\frac{1-\lambda}{\lambda} b\right)+d_{L} V(1-h)\right] \\
& +v_{L H}\left[U(b)+d_{H} V(1-\alpha h)\right]+v_{L L}\left[U\left(b+d_{L} V(1-\alpha h)\right]\right.
\end{aligned}
$$

to be maximized wrt. $b$ and $\alpha$ under the constraint.

$$
b \leq \widehat{b}\left(\lambda, w_{H}, d_{H}, \alpha\right)
$$

This is a Kuhn-Tucker problem with the first order conditions

$$
\begin{aligned}
& \frac{\partial \Delta}{\partial b}=-\left[v_{H H} U^{\prime}\left(w_{H}-\frac{1-\lambda}{\lambda} b\right)+v_{H L} U^{\prime}\left(w_{H}-\frac{1-\lambda}{\lambda} b\right)\right] \frac{1-\lambda}{\lambda} \\
&+v_{L H} U^{\prime}(b)+v_{L L} U^{\prime}(b)-\mu \\
&= 0 \\
& \frac{\partial \Delta}{\partial \alpha}=-v_{L H} V^{\prime}(1-\alpha h) d_{H} h-v_{L L} V^{\prime}(1-\alpha h) d_{L} h+\mu \widehat{b}_{\alpha}=0 \\
& \mu\left[b-\widehat{b}\left(\lambda, w_{H}, d_{H}, \alpha\right)\right]=0
\end{aligned}
$$

where $\mu$ is the multiplier associated with the constraint (9).

Our interest is in the situation where the constraint is binding $\mu>0$, and we consider whether the optimal utilitarian policy includes workfare $(\alpha>0)$. We have that

$$
\frac{\partial \Delta}{\partial \alpha}=-\left[v_{L H}+v_{L L} \frac{d_{L}}{d_{H}}\right] V^{\prime}(1-\alpha h) d_{H} h+\mu \widehat{b}_{\alpha}
$$

and

implying

$$
\widehat{b}_{\alpha}=\frac{V^{\prime}(1-a h) d_{H} h}{\frac{1-\lambda}{\lambda} U^{\prime}\left(w_{H}-\frac{1-\lambda}{\lambda} \widehat{b}\right)+U^{\prime}(\widehat{b})}
$$

$$
\begin{aligned}
\mu & =-U^{\prime}\left(w_{H}-\frac{1-\lambda}{\lambda} b\right)\left[v_{H H}+v_{H L}\right] \frac{1-\lambda}{\lambda}+\left[v_{L H}+v_{L L}\right] U^{\prime}(b) \\
& =-U^{\prime}\left(w_{H}-\frac{1-\lambda}{\lambda} b\right) \lambda \frac{1-\lambda}{\lambda}+[1-\lambda] U^{\prime}(b) \\
& =\left[U^{\prime}(b)-U^{\prime}\left(w_{H}-\frac{1-\lambda}{\lambda} b\right)\right][1-\lambda]
\end{aligned}
$$


hence

$$
\mu \widehat{b}_{\alpha}=\left[U^{\prime}(b)-U^{\prime}\left(w_{H}-\frac{1-\lambda}{\lambda} b\right)\right][1-\lambda] \frac{d_{H} V^{\prime}(1-a h) h}{\frac{1-\lambda}{\lambda} U^{\prime}\left(w_{H}-\frac{1-\lambda}{\lambda} b\right)+U^{\prime}(b)}
$$

The strategy is to find a condition ensuring that $\left.\frac{\partial \Delta}{\partial \alpha}\right|_{\alpha=0}>0$. This is the case if

$$
\mu \widehat{b}_{\alpha}>\left[v_{L H}+v_{L L} \frac{d_{L}}{d_{H}}\right] V^{\prime}(1-\alpha h) d_{H} h
$$

which holds if

$$
\begin{aligned}
& {\left[U^{\prime}(\widehat{b}(0))-U^{\prime}\left(w_{H}-\frac{1-\lambda}{\lambda} \widehat{b}(0)\right)\right][1-\lambda] \frac{d_{H} V^{\prime}((1-a h)) h}{\frac{1-\lambda}{\lambda} U^{\prime}\left(w_{H}-\frac{1-\lambda}{\lambda} \widehat{b}(0)\right)+U^{\prime}(\widehat{b}(0))} } \\
> & {\left[v_{L H}+v_{L L} \frac{d_{L}}{d_{H}}\right] V^{\prime}(1-\alpha h) d_{H} h } \\
& \text { or }
\end{aligned}
$$

$$
\begin{aligned}
& {\left[U^{\prime}(\widehat{b}(0))-U^{\prime}\left(w_{H}-\frac{1-\lambda}{\lambda} \widehat{b}(0)\right)\right][1-\lambda] } \\
> & {\left[v_{L H}+v_{L L} \frac{d_{L}}{d_{H}}\right]\left[\frac{1-\lambda}{\lambda} U^{\prime}\left(w_{H}-\frac{1-\lambda}{\lambda} \widehat{b}(0)\right)+U^{\prime}(\widehat{b}(0))\right] }
\end{aligned}
$$

This can be rewritten

$$
\begin{aligned}
& {\left[U^{\prime}(\widehat{b}(0))-U^{\prime}\left(w_{H}-\frac{1-\lambda}{\lambda} \widehat{b}(0)\right)\right][1-\lambda] } \\
> & {\left[v_{L H}+v_{L L} \frac{d_{L}}{d_{H}}\right]\left[U^{\prime}\left(w_{H}-\frac{1-\lambda}{\lambda} \widehat{b}(0)\right)+\lambda\left[U^{\prime}(\widehat{b}(0))-U^{\prime}\left(w-\frac{1-\lambda}{\lambda} \widehat{b}(0)\right)\right]\right] \frac{1}{\lambda} }
\end{aligned}
$$

or

$$
\begin{aligned}
& {\left[U^{\prime}(\widehat{b}(0))-U^{\prime}\left(w_{H}-\frac{1-\lambda}{\lambda} \widehat{b}(0)\right)\right]\left[v_{L L} \frac{d_{H}-d_{L}}{d_{H}}\right] } \\
> & {\left[v_{L H}+v_{L L} \frac{d_{L}}{d_{H}}\right] U^{\prime}\left(w_{H}-\frac{1-\lambda}{\lambda} \widehat{b}(0)\right) \frac{1}{\lambda} }
\end{aligned}
$$

which in turn yields

$$
\frac{U^{\prime}(\widehat{b}(0))-U^{\prime}\left(w_{H}-\frac{1-\lambda}{\lambda} \widehat{b}(0)\right)}{U^{\prime}\left(w_{H}-\frac{1-\lambda}{\lambda} \widehat{b}(0)\right)}>\frac{v_{L H} d_{H}+v_{L L} d_{L}}{v_{L L}\left[d_{H}-d_{L}\right]} \frac{1}{\lambda}
$$


or

$$
\frac{U^{\prime}(\widehat{b}(0))-U^{\prime}\left(w_{H}-\frac{1-\lambda}{\lambda} \widehat{b}(0)\right)}{U^{\prime}\left(w_{H}-\frac{1-\lambda}{\lambda} \widehat{b}(0)\right)}>\left[\frac{1-\lambda}{v_{L L}} \frac{d_{H}}{d_{H}-d_{L}}-1\right] \frac{1}{\lambda}
$$

Notice that this condition is always fulfilled for $\lambda=1$.

\section{APPENDIX C: Allowing $\mu_{H}$-types to re- ceive benefits}

The text considers the screening problem of preventing the $\mathrm{HH}$-type from getting the benefit. It may be questioned whether that is to the $L L$-type. Is it always the case that benefits for the $L L$-type can be higher if the HH-type works and contributes taxes rather than claiming benefits along with the low ability types?

If the $H H$-type also receives the benefit, the budget constraint reads (this is in the following denoted the non-screening (ns) case)

$$
v_{H L} T_{n s}=\left(1-v_{H L}\right) b_{n s}
$$

The selection problem is now to ensure that the $H L$-type is better off working, and this requires

$$
U\left(w_{H}-T_{n s}\right)+d_{L} V(1-h)>U\left(b_{n s}\right)+d_{L} V(1-\alpha h)
$$

or using that $T_{n s}=\frac{1-v_{H L}}{v_{H L}} b_{n s}$ we have that $b_{n s}$ is determined by

$$
U\left(w_{H}-\frac{1-v_{H L}}{v_{H L}} b_{n s}\right)+d_{L} V(1-h)=U\left(b_{n s}\right)+d_{L} V(1-\alpha h)
$$

Is the $L L$-type better off in the screening or in the no screening case? This is the case if

$$
U\left(b_{s}\right)+d_{L} V(1-\alpha h)>U\left(b_{n s}\right)+d_{L} V(1-\alpha h)
$$

or

$$
b_{s}>b_{n s}
$$

Note that this comparison is made for the same level of workfare $\alpha$ in the two regimes.

From the text we know that $b_{s}$ is determined by

$$
U\left(w_{H}-\frac{1-\lambda}{\lambda} b_{s}\right)+d_{H} V(1-h)=U\left(b_{s}\right)+d_{H} V(1-\alpha h)
$$


Comparing the two requimes (10) and (11) yields

$$
\begin{aligned}
& U\left(w_{H}-\frac{1-v_{H L}}{v_{H L}} b_{n s}\right)+d_{L} V(1-h)-U\left(w_{H}-\frac{1-\lambda}{\lambda} b_{s}\right)-d_{H} V(1-h) \\
= & U\left(b_{n s}\right)+d_{L} V(1-\alpha h)-U\left(b_{s}\right)-d_{H} V(1-\alpha h)
\end{aligned}
$$

or

$$
\begin{aligned}
& {\left[d_{L}-d_{H}\right][V(1-h)-V(1-\alpha h)] } \\
= & U\left(b_{n s}\right)-U\left(w_{H}-\frac{1-v_{H L}}{v_{H L}} b_{n s}\right)-\left[U\left(b_{s}\right)-U\left(w_{H}-\frac{1-\lambda}{\lambda} b_{s}\right)\right]
\end{aligned}
$$

We have that $V(1-h)-V(1-\alpha h)>0$ for $\alpha<1$ and $d_{L}-d_{H}<0$. Hence the LHS of this expression is always negative. Turning to the RHS, we have that evaluated for a given benefit level $b$ is positive since

$$
\begin{aligned}
& U(b)-U\left(w_{H}-\frac{1-v_{H L}}{v_{H L}} b\right)-\left[U(b)-U\left(w_{H}-\frac{1-\lambda}{\lambda} b\right)\right] \\
= & U\left(w_{H}-\frac{1-\lambda}{\lambda} b\right)-U\left(w_{H}-\frac{1-v_{H L}}{v_{H L}} b\right)>0
\end{aligned}
$$

This follows straightforward from the fact that $\lambda \geq v_{H L}$. Hence for (12) to hold we need $b_{s}>b_{n s}$. The intuition is that in the screening case more are paying taxes and fewer claiming benefits, and therefore the benefit level can be higher while still satisfying the self-selection constraint. 